\title{
Synthesis of (E)-5-(2-Radioiodovinyl)arabinosyl Uridine Analog for Probing HSV-1 Thymidine Kinase Gene ${ }^{1}$
}

\author{
Chung-Shan Yu, ${ }^{*}$ Chien-Hung Wu, Li-Wu Chiang, Ren-Tsong Wang, Heng-Yen Wang, Chien-Hung Yeh, and Kun-I Lin \\ Department of Nuclear Science, National Tsing-Hua University, No. 101 Sec. 2, Guang-Fu Rd., Hsinchu, 300, Taiwan
}

(Received July 19, 2005; CL-050927)

\begin{abstract}
The genetic probe labeled with positron emitter for monitoring tumor cells transfacted by herpes simplex virus thymidine kinase gene has been intensively studied. A useful synthetic methodology was developed to synthesize (E)-5-[2-(tributylstannyl)vinyl]arabinosyl uridine (TSVAU) and to radiolabel (E)-5-\{2-[ ${ }^{125}$ I] iodovinyl $\}$ arabinosyl uridine (IVAU) substrate for herpes simplex virus type- 1 thymidine kinase gene. The synthesis started from arabinosyl uridine via six steps to provide TSVAU in $18 \%$ yield. The subsequent radiolabeling with Na$\left[{ }^{125} \mathrm{I}\right] \mathrm{I}$ under oxidation provided $\left[{ }^{125} \mathrm{I}\right] \mathrm{IVAU}$ in $80 \%$ radiochemical yield.
\end{abstract}

Gene therapy has become one of the most promising approaches for cancer treatment. The mechanism underlying the therapy starts by delivering the suicide gene into the target cells, followed by administering the prodrugs. The presence of the suicide gene in the target cells activates the prodrugs, such as nucleoside analogs, to form toxic metabolites, which then initiate the subsequent suicidal mechanism. The most intensively studied suicide gene, HSV-1 TK (herpes simplex virus thymidine kinase), can serve bi-functionally as both therapeutic and reporter genes in this system. ${ }^{2}$ Moreover, in vivo gene expression of HSV-1 TK can be successfully monitored by imaging its substrate analog, usually a nucleoside analog. After being phosphorylated by viral TK, the metabolite can be randomly incorporated into elongating DNA chains by cellular enzymes. ${ }^{3}$ The localization of this event could be traced down by using a tagged nucleoside analog. Of the most excellent candidates for in vivo studies are which radiolabeled with positron emitters owing to their higher imaging quality and quantification capacity. For example, $\left[{ }^{124}\right.$ I]FIAU (pyrimidine nucleoside) and $\left[{ }^{18} \mathrm{~F}\right] \mathrm{FHBG}(\mathrm{pu}-$ rine nucleoside) have been coupled with PET (positron emission tomography) to provide invaluable images (Scheme 1).,

Recently, an investigation on bioactivity-guided screening of nucleosides as substrates for HSV-1 TK by Degrève et al. discovered two potential compounds: IaraU (5-iodoarabinosyl uridine) and IVAU $\{(E)-5$-(2-iodovinyl)arabinosyl uridine $\} \mathbf{1}$ (Scheme 2). ${ }^{6}$ As part of our systematic syntheses of radiolabeled thymidine analogs, ${ }^{7}$ we have developed a facile synthesis of the former compound $\left[{ }^{125} \mathrm{I}\right] \mathrm{IaraU} .{ }^{8}$ Though the syntheses of $\left[{ }^{123} \mathrm{I}\right]$ IVAU and its precursor TSVAU $\{(E)-5$-[2-(tributylstannyl)vinyl]arabinosyl uridine $\mathbf{2}$ have been reported by Dougan et al., the use of acetylene during production of trans-1,2-distannyl ethene was a formidable procedure for the most medicinal chemistry laboratories. ${ }^{9}$ Consequently, an alternative precursor bearing trimethylsilyl vinyl group was developed by Morin et al. and [ $\left.{ }^{125} \mathrm{I}\right] \mathrm{IVAU} \mathbf{1}$ could be prepared in fair yield. ${ }^{10}$

In view of the potential application of organotin to radiolabeling with positron emitter ${ }^{18} \mathrm{~F}$, we developed a practical preparation of the 2 -deoxy moieties of TSVAU and demonstrat-

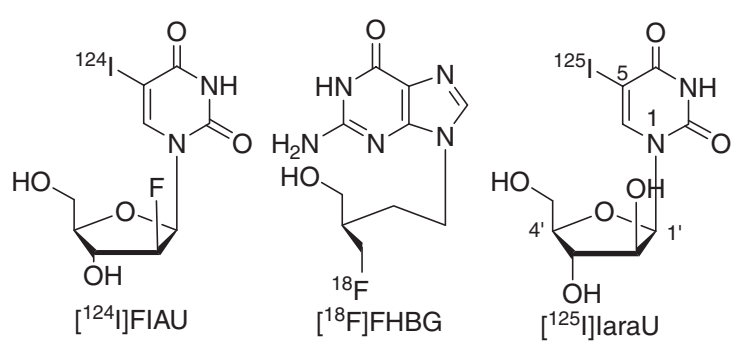

Scheme 1. Recently developed genetic probes.

ed their usefulness in radiolabeling with radio bromine and fluorine. $^{7 \mathrm{a}-7 \mathrm{c}}$ These $2^{\prime}$-deoxy nucleosides usually suffer from the easy cleavage by phosphorylase in vivo, however. Aiming to develop a longer half-life genetic probe for the in vivo study, we describe here a facile synthesis of TSVAU and its radiolabeling leading to [ $\left.{ }^{125} \mathrm{I}\right] \mathrm{IVAU}$. This synthesis should be able to apply to positron-emitter-labeling chemistry accordingly.

The whole synthesis started from the commercial arabinosyl uridine 3, which could be easily prepared according to the reported procedure (Scheme 2). ${ }^{8,11}$ Through the iodination, the Heck coupling reaction and the removal of the silyl group, compound $\mathbf{6}$ was obtained in good yield. Whereas an attempt to purify $\mathbf{6}$ by using repeated column chromatography was not successful, the impurities could be removed during subsequent stannylation and satisfactory elemental analysis of compound

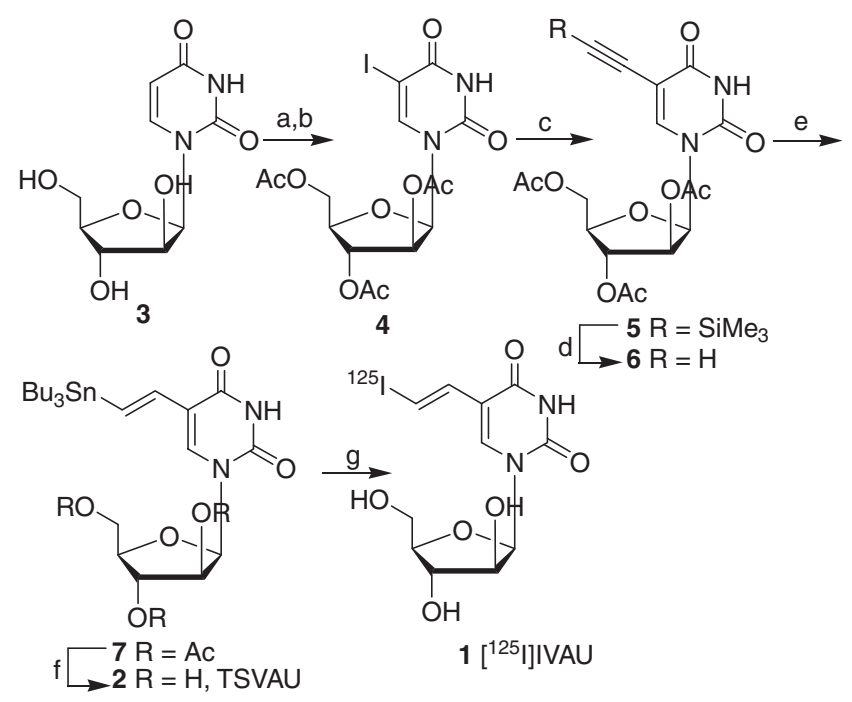

Scheme 2. Reaction conditions: (a): $\mathrm{Ac}_{2} \mathrm{O} /$ pyridine; (b): $\mathrm{I}_{2}$, $\mathrm{CAN}, \mathrm{CH}_{3} \mathrm{CN}, 88 \%$; (c) trimethylsilyl ethyne, $\mathrm{CuI},\left(\mathrm{PPh}_{3}\right)_{2}$ $\mathrm{PdCl}_{2}, \mathrm{DMF}, 80 \%$; (d) KF, $\mathrm{NEt}_{4} \mathrm{Br}, \mathrm{CH}_{3} \mathrm{CN}, 63 \%$; (e) $\mathrm{HSnBu}_{3}$, AIBN, toluene, 80\%; (f) $\mathrm{NaOMe} / \mathrm{MeOH}, \mathrm{H}^{+}$, $\approx 50 \%$; (g) $\mathrm{Na}-$ $\left[{ }^{125} \mathrm{I}\right] \mathrm{I}, \mathrm{H}_{2} \mathrm{O}_{2}$, HPLC, $80 \%$. 


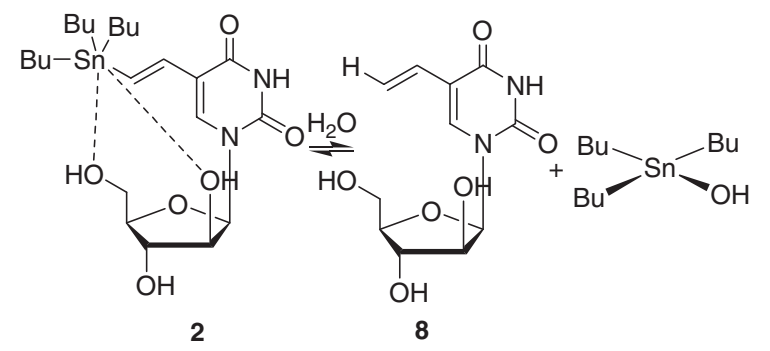

Scheme 3. Proposed chelating effect leading to destannylation.

7 could be obtained. Likewise, the next deprotection of 7 encountered the same difficulties; a satisfactory elemental analysis of $\mathbf{2}$ was not available. ${ }^{12}$ The byproduct 5-vinyl araU $\mathbf{8}$ was easily formed through a proposed water-catalyzed destannylation (Scheme 3). ${ }^{8}$

In comparison with the recently described 5-trimethylstannyl araU, ${ }^{8}$ such an instability derived from chelating effect in compound $\mathbf{2}$ was relatively mild. It is probably because the bulky $n$-butyl groups decrease the adequate formation of coordination complex to a certain extent. During radioiodination (Scheme $2 \mathrm{~g}$ ), we found the best yield ( $80 \%)$ of $\mathbf{1}$ was obtained in $20 \mathrm{~min}$ (Figure 1). In comparison with the usual high yield of $99 \%$ within one minute as reported for the 2 -deoxy and 2 '-fluoro analogs,${ }^{7 \mathrm{a}, 13}$ the $2^{\prime}-\mathrm{OH}$ group might interfere with the electrophilic attack through iodine. The stereochemistry of $(E)$-isomer $\mathbf{1}$ was confirmed from the spectra of the authentic sample prepared via the same synthetic route but without radioactivity. Data of ${ }^{1} \mathrm{H}-$ NMR unambiguously indicated the identity of the sole isomer corresponding to $(E)-\mathbf{1}$.

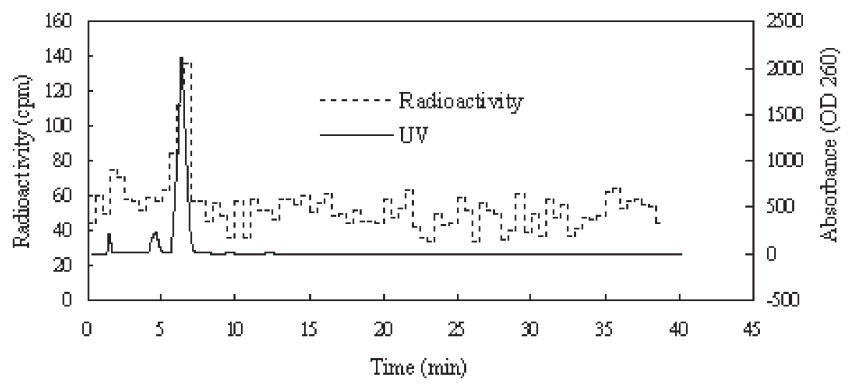

Figure 1. HPLC chromatogram of 5-[ $\left.{ }^{125} \mathrm{I}\right] \mathrm{IVAU} \mathbf{1}$.

In brief, we established a practical preparation of TSVAU 2 and demonstrated its application to radioiodination. The present method provided the base for incorporation of the positron emitter [ $\left.{ }^{124} \mathrm{I}\right] \mathrm{I}-$. Additionally, a well protected analog of $\mathbf{2}$ should be capable of radiolabeling with $\left[{ }^{18} \mathrm{~F}\right] \mathrm{F}_{2}$ by adopting our recently reported method. ${ }^{7 \mathrm{a}-7 \mathrm{c}}$

We thank National Science Council, Taiwan for providing financial support (NSC-93-2113-M-007-038).

\section{References and Notes}

1 Dedicated to Professor Jiunn-Guang Lo on occasion of his 65th birthday.

2 For reviews see: a) I. Peñuelas, J. F. Boán, J. M. Martí-Climent, B. Sangro, G. Mazzolini, J. Prieto, and J. A. Richter, Mol. Imaging Biol., 6, 225 (2004). b) H. R. Herschman, Crit. Rev. Oncol./Hematol., 51, 191 (2004). c) H. R. Herschman, J. Cell. Biochem., 39, Suppl., 36 (2002). d) S. J. Advanil, R. R. Weichselbaum, R. J. Whitley, and B. Roizman, Clin. Microbiol.
Infect., 8, 551 (2002).

3 a) E. F. J. deVries, A. R. Buursma, G. A. P. Hospers, N. H. Mulder, and W. Vaalburg, Curr. Pharm. Des., 8, 1435 (2002). b) S. S. Gambhir, H. R. Herschman, and S. R. Cherry, Neoplasia, 2, 118 (2002). c) C. Nichol and E. E. Kim, J. Nucl. Med., 42, 1368 (2001). d) R. E. Gibson, H. D. Burns, T. G. Hamill, W. S. Eng, B. E. Francis, and C. Ryan, Curr. Pharm. Des., 6, 973 (2000).

4 For [ ${ }^{124}$ I]-FIAU: a) M. V. Simoes, M. Miyagawa, S. Reder, C. Stadele, R. Haubner, W. Linke, T. Lehner, P. Epple, M. Anton, M. Schwaiger, and F. M. Bengl, J. Nucl. Med., 46, 98 (2005). b) S. A. Soghomonyan, M. Doubrovin, J. Pike, X. Luo, M. Ittensohn, J. D. Runyan, J. Balatoni, R. Finn, J. G. Tjuvajev, R. Blasberg, and D. Bermudes, Cancer Gene Ther., 12, 101 (2005). c) B. X. Wen, P. Burgman, P. Zanzonico, J. O’Donoghue, S. D. Cai, R. Finn, I. Serganova, R. Blasberg, J. Gelovani, G. C. Li, and C. C. Ling, Eur. J. Nucl. Med. Mol. Imaging, 31, 1530 (2004).

5 For $\left[{ }^{18}\right.$ F]-FHBG: a) S. S. Yaghoubi, J. R. Barrio, M. Namavari, N. Satyamurthy, M. E. Phelps, H. R. Herschman, and S. S. Gambhir, Cancer Gene Ther., 12, 329 (2005). b) L. A. Green, K. Nguyen, B. Berenji, M. Iyer, E. Bauer, J. R. Barrio, M. Namavari, N. Satyamurthy, and S. S. Gambhir, J. Nucl. Med., 45, 1560 (2004). c) D. E. Ponde, C. S. Dence, D. P. Schuster, and M. J. Welch, Nucl. Med. Biol., 31, 133 (2004).

6 B. Degrève, R. Esnouf, E. De Clercq, and J. Balzarini, Mol. Pharmacol., 58, 1326 (2000).

7 a) C.-S. Yu, J. Eisenbarth, A. Runz, K. Weber, S. Zeisler, and F. Oberdorfer, J. Label. Compd. Radiopharm., 46, 421 (2003). b) C.-S. Yu and F. Oberdorfer, Nucleos. Nucleot. Nucl., 22, 71 (2003). c) C.-S. Yu and F. Oberdorfer, Synlett, 2000, 86. d) C.-S. Yu and F. Oberdorfer, Synthesis, 1999, 2057.

8 Manuscript "Synthesis of 5-radioiodoarabinosyl Uridine Analog for Probing HSV-1 Thymidine Kinase Gene: An Unexpected Chelating Effect," submitted.

9 H. Dougan, B. A. Rennie, D. M. Lyster, and S. L. Sacks, Appl. Radiat. Isot., 45, 795 (1994).

10 a) K. W. Morin, D. Atrazheva, E. E. Knaus, and L. I. Wiebe, J. Med. Chem., 40, 2184 (1997). b) K. W. Morin, E. E. Knaus, and L. I. Wiebe, Nucl. Med. Commun., 18, 599 (1997).

11 a) H. Ozaki, K. Nakajima, K. Tatsui, C. Izumi, M. Kuwahara, and H. Sawai, Bioorg. Med. Chem. Lett., 13, 2441 (2003). b) S. F. Wnuk, S. M. Chowdhury, J. P. I. Garcia, and M. J. Robins, J. Org. Chem., 67, 1816 (2002).

12 Preparation of 1-( $\beta$-D-arabinofuranosyl)-(E)-5-[2-(tributylstannyl)vinyl]pyrimidin-2,4(3H)-dione 2: To compound 7 (15 mg, $0.022 \mathrm{mmol}$ ) in $\mathrm{MeOH}(3 \mathrm{~mL})$ was added $\mathrm{NaOMe} / \mathrm{MeOH}$ ( $1 \mathrm{~mL}, 6 \mathrm{mM}, 0.3$ equiv.). TLC ( $\left.\mathrm{MeOH} / \mathrm{CHCl}_{3} 3: 17\right)$ indicated the formation of product $2\left(R_{f}=0.65\right)$ and byproduct 5-vinyl araU $8\left(R_{f}=0.25\right)$, and the consumption of starting material $7\left(R_{f}=0.97\right)$. The mixture was treateded with cation exchange resin (Dowex $500 \mathrm{WX} 8-400, \mathrm{H}^{+}$form) and filtered. The filtrate was concentrated under reduced pressure at $30^{\circ} \mathrm{C}$ to provide 2 and byproduct 8 in $80 \%$ yield $(9 \mathrm{mg}$ ) with a ratio of greater than $1: 1$. We also found that during NMR experiment, the ratio was significantly decreased to $1: 3$. It might be due to the trace water which accelerated the destannylation. A further purification using column chromatography was not necessary, since the yield was reduced dramatically. In our hands, about $50 \%$ yield of $\mathbf{2}$ was usually obtained. The mixture of $\mathbf{2}$ and $\mathbf{8}$ was directly used for the next radioiodination. White solids $(2+8)$. Spectroscopic data was provided in the Supporting Information.

13 a) G. Vaidyanathan and M. R. Zalutsky, Nucl. Med. Biol., 25, 487 (1998). b) J. Toyohara and Y. Fujibayashi, Nucl. Med. Biol., 30, 681 (2003). 